\title{
Induction chemotherapy plus concurrent chemoradiotherapy versus induction chemotherapy plus volumetric modulated arc therapy alone in the treatment of stage II-IVB nasopharyngeal carcinoma patients: a retrospective controlled study
}

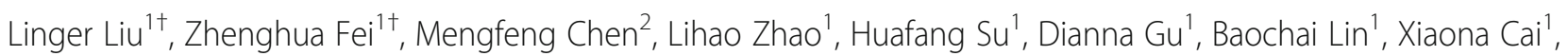
Lihuai Lu', Mengdan Gao ${ }^{1}$, Xuxue Ye ${ }^{1}$, Xiance Jin ${ }^{1^{*}}$ and Congying Xie ${ }^{1 *}$

\begin{abstract}
Background: In the era of intensity-modulated radiotherapy (IMRT), the role of additional concurrent chemotherapy (CC) to radiotherapy (RT) after induction chemotherapy (IC) compared to IC followed by RT alone remains unclear for stage II-IVB nasopharyngeal carcinoma (NPC) patients. The aim of this study was to evaluate the efficacy and toxicities of IC/RT and IC/CCRT in the treatment of NPC with volumetric modulated arc therapy (VMAT).
\end{abstract}

Methods: From January 2012 to March 2016, a total of 217 NPC patients were retrospectively assessed. Of the 217 patients, 139 patients received IC followed by VMAT alone and 78 patients received IC plus CCRT. Overall survival (OS), progression-free survival (PFS) and toxicities were assessed.

Results: The 5-year OS, PFS rates were 57.5\%, 41.8\% and 47.8\%, 38.4\% for the IC/RT and IC/CCRT arms, respectively, without significant difference in survival between the two groups (both $p>0.05$ ). Multivariate analysis indicated that treatment modality (IC/RT vs. IC/CCRT) was not an independent prognostic factor for OS or PFS. Grade 3-4 leukopenia/ neutropenia (3.60\% vs. 20.51\%, $p<0.001$ ), gastrointestinal disorder (nausea/vomiting/diarrhea, $2.16 \%$ vs. 41.03\%, $p<0.001$ ), mucositis ( $29.50 \%$ vs. $47.44 \%, p=0.01$ ) and xerostomia (34.53\% vs. $48.72 \%, p=0.04$ ) were more frequent in the IC/ CCRT arm than in the IC/RT arm during VMAT.

Conclusions: No significant difference in OS and PFS was observed between IC plus VMAT alone and IC/CCRT in the treatment of stage II-IVB NPC patients, however, more side effects were observed in the IC/CCRT arm.

Keywords: Nasopharyngeal carcinoma, Concurrent chemotherapy, Volumetric modulated arc therapy, Toxicity, Survival outcome

\footnotetext{
*Correspondence: jinxc1979@hotmail.com; xiecy@wzhospital.cn; wzxiecongying@163.com

†Linger Liu and Zhenghua Fei contributed equally to this work.

'Department of Radiation and Medical Oncology, The First Affiliated Hospital

of Wenzhou Medical University, No.2 Fuxue Lane, Wenzhou 325000, China

Full list of author information is available at the end of the article
}

(c) The Author(s). 2018 Open Access This article is distributed under the terms of the Creative Commons Attribution 4.0 International License (http://creativecommons.org/licenses/by/4.0/), which permits unrestricted use, distribution, and reproduction in any medium, provided you give appropriate credit to the original author(s) and the source, provide a link to the Creative Commons license, and indicate if changes were made. The Creative Commons Public Domain Dedication waiver (http://creativecommons.org/publicdomain/zero/1.0/) applies to the data made available in this article, unless otherwise stated. 


\section{Background}

Nasopharyngeal carcinoma (NPC) is endemic in Southern China, with an annual incidence of 15-50 cases per 100,000 [1]. Due to its high sensitivity to chemotherapy and radiotherapy, combined chemotherapy and radiotherapy has been the standard treatment modality for stage II-IVB NPC as recommended in the NCCN guidelines [2].

The strategy of induction chemotherapy (IC) followed by concurrent chemoradiotherapy (CCRT) is widely applied for NPC patients in China. Studies demonstrated that IC followed by CCRT significantly improved survival in NPC [3-5]. Promising results of IC/CCRT in NPC with 3-year progression-free survival (PFS) and overall survival (OS) rates of 88.2 and $94.1 \%$ [6], and 5 -year OS rate of $78 \%$ [7], respectively were also reported. However, high incidences of grade 3/4 adverse events were observed during concurrent chemotherapy (CC) and many patients failed to complete the course of CC due to drug-related toxicities in clinical practice [811]. On the other hand, similar survival outcomes between IC/RT and IC/CCRT arms had been demonstrated by some trials $[12,13]$. Encouraging results of IC followed by $\mathrm{RT}$ alone with benefit in response rate (RR) [14] and improvement in disease-free survival (DFS) [14, 15] had also been reported. To our knowledge, it remains controversial whether the addition of $\mathrm{CC}$ to $\mathrm{RT}$ after IC (IC/CCRT) improves the efficacy of treatment compared with IC/RT.

Intensity modality radiotherapy (IMRT), especially new IMRT delivery modality volumetric modulated arc therapy (VMAT) has widely replaced the conventional radiotherapy due to its better dose painting ability and efficacy in the treatment of NPC [16-18]. Therefore, we assume that IC plus IMRT alone might be a feasible option with reduced toxicities in the treatment of NPC. What is more, most previous studies were based on conventional radiotherapy. Few studies compared the outcomes between IC/ RT and IC/ CCRT arms with VMAT in the treatment of NPC. Therefore, the aim of this study was to evaluate the efficacy and toxicities of IC/RT and IC/CCRT with VMAT in the treatment of stage II-IVB NPC patients.

\section{Methods \\ Patients}

We retrospectively reviewed all NPC patients underwent chemotherapy and VMAT from January 2012 to March 2016 in author's institution. The flow diagram for study design of this study was shown in Fig. 1. Patients were divided into two arms: IC/RT and IC/CCRT. Patients in these two groups were matched for seven characteristics: age ( $\leq 54$ years vs. $>54$ years), sex (male vs. female), $\mathrm{T}$ category (T1 vs. T2 vs. T3 vs. T4), N category (N0 vs. $\mathrm{N} 1$ vs. N2 vs. N3), clinical stage (II vs. III vs. IVA vs. IVB), IC regimen (cisplatin plus fluorouracil (FP) vs. docetaxel/paclitaxel plus cisplatin (TP) vs. other) and number of IC cycles ( $\leq 2$ vs. $>2$ cycles).

Inclusion criteria for this study were as follows: (i) New histologically confirmed NPC; (ii) Stage II-IVB at diagnosis (the 7th edition of American Joint Committee on Cancer) [2]; (iii) Aged 16 to 75 years-old; (iv) Adequate liver, renal and hematologic function (absolute neutrophil $\geq 1.5 \times 10^{9} / \mathrm{L}$ or platelet count $\geq 100 \times 10^{9} / \mathrm{L}$ ); (v) Karnofsky performance score $\geq 70$; (vi) No previous malignancy or other concomitant malignant disease; (vii) No prior anti-cancer treatment. The exclusion criteria

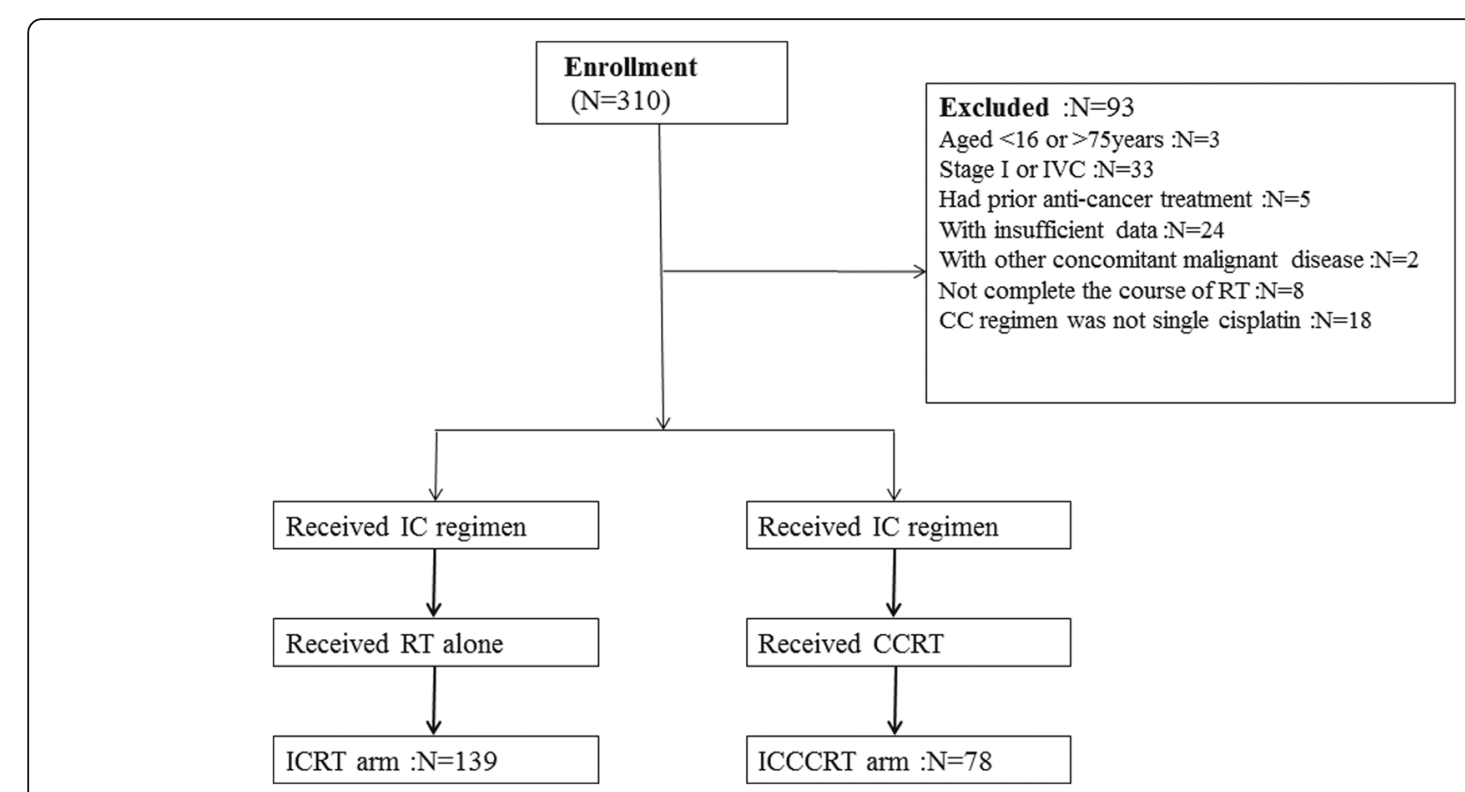

Fig. 1 Inclusion and exclusion criteria flow diagram of all patients 
were: (i) Age $<16$ or $>75$ years-old; (ii) Stage I or stage IVC NPC; (iii) Pregnancy; (iv) Patients with insufficient data. This study was approved by the Institutional Review Board and performed at author's institution.

\section{Treatment}

All patients underwent VMAT with simultaneous integrated boost (SIB) technique 2 weeks after IC. Target and normal tissue delineations have been reported in our previous study and generalized here only briefly. Gross tumor volume (GTV) was delineated as the mass shown in the enhanced CT images and/or MRI images, including the nasopharyngeal tumor, retropharyngeal lymphadenopathy, and enlarged neck nodes. For the GTV of the primary tumor, involved retropharyngeal lymph nodes and intracavity lesions were delineated according to the post-IC volume, whereas involved tissues (eg, pterygopalatine fossa) were delineated according to the pre-IC volume of the primary lesion as shown by MRI. Post- IC volumes were used to delineate the rest involved lymph nodes. Clinical target volume (CTV) was defined as the GTV plus a margin of potential microscopic spread. Planning target volume (PTV) was created by adding a $3 \mathrm{~mm}$ margin to the CTV to account for setup variability [19].

Prescription doses were 70 Gy and 56 Gy for GTV and CTV in 28 fractions, respectively. OARs consisting of the brainstem, spinal cord, left and right parotids were included for optimization. Dual arc VMAT plans were generated on Philips Pinnacle ${ }^{3}$ treatment planning system (TPS) (clinical version 9.2; Philips, Fichburg, WI, USA). Optimization parameters and process have been reported in our previous study. Briefly, the first arc rotates clockwise with a start angle of $181^{\circ}$ and a stop angle of $180^{\circ}$, and the second arc rotates counterclockwise from $180^{\circ}$ to $181^{\circ}$. During the optimization, leaf motion of $0.46 \mathrm{~cm} / \mathrm{deg}$. and a final arc space degree of 4 were employed [16].

Induction chemotherapy was composed of TP, FP, and gemcitabine plus cisplatin. All regimens were given every 3 weeks. The concurrent chemotherapy regimen was $80-100 \mathrm{mg} / \mathrm{m}^{2}$ cisplatin on day 1 every 3 weeks for 2-3 courses.

\section{Assessments and follow-up}

The efficacy of treatment was evaluated according to the Response Evaluation Criteria in Solid Tumors (RECIST) version 1.1 at two time points: at the end of RT, and 3 months after RT. Chemotherapy-related toxicities were evaluated according to the Common Terminology Criteria for Adverse Events (CTCAE, version 3.0). RT-induced toxicities were graded according to the Acute and Late Radiation Morbidity Scoring Criteria of the Radiation Therapy Oncology Group. Patients were evaluated weekly during treatment and every 3 months for the first 3 years, every 6 months in the fourth and fifth years and annually thereafter until death. Each follow-up included physical examination, blood count measurement, liver function test, renal function test, neurologic examination, endoscopic biopsy, computed tomography (CT) scan and magnetic resonance imaging (MRI). Additional examinations were performed to evaluate distant metastasis or local relapse when indicated.

\section{Endpoints and statistical analysis}

The study's end points were OS (time from treatment to death of any cause or last follow-up), PFS (interval between the initiation of treatment to first disease progression, including local recurrence, distant metastasis or death due to NPC), and treatment-related toxicities. If the complete survival time was impossible to obtain or the disease did not progress, the patient's status was assumed as the last known survival and/or contact date. Characteristics of patients and treatment-related adverse effects were compared using Pearson chi-square or Fisher's exact tests. Survival rates and univariate analyses were estimated by Kaplan-Meier method and compared with log-rank test. Multivariate analyses were calculated using Cox proportional hazard model. All statistical analyses were performed using SPSS (version 22.0, SPSS Inc., Chicago, IL). Two-tailed $P$-values $<0.05$ were considered statistically significant.

\section{Results}

\section{Baseline characteristics}

Ultimately, 217 patients with stage II-IVB NPC who had been treated with IC/RT or IC/CCRT were enrolled in this study, where 139 patients received IC followed by VMAT alone and 78 patients received IC plus CCRT, respectively. Baseline characteristics of patients were presented in Table 1 with a median age of 54 years old (range: 16-75 years). There were 166/217 (76.50\%) male and $51 / 217(23.50 \%)$ female patients, respectively, where patients in stage II, III, IVA and IVB NPC were 64/217 (29.49\%), 113/217 (52.07\%), 26/217 (11.98\%) and 14/217 (6.45\%), respectively.

All patients completed the full course of VMAT. For IC treatment, 45 patients completed one cycle, 83 patients completed two cycles and 89 patients completed three or more cycles; 155 patients received the TP regimen and 29 patients received the FP regimen. Two patients did not complete the course of CC due to severe toxicities in the IC/CCRT arm.

\section{Response and survival outcomes}

Treatment response was assessed for all patients 3 months after radiotherapy. The disease control rate (DCR) and objective response rate (ORR) for IC/RT and IC/CCRT arms 
Table 1 Characteristics of nasopharyngeal carcinoma patients with stage II-IVB

\begin{tabular}{|c|c|c|c|}
\hline & ICRT arm (\%) & ICCCRT arm (\%) & $P$-value \\
\hline Age (years) & & & 0.55 \\
\hline$\leq 54$ years & 69 (49.64) & $42(53.85)$ & \\
\hline$>54$ years & 70 (50.36) & $36(46.15)$ & \\
\hline Sex & & & 0.66 \\
\hline Male & 105 (75.54) & $61(78.21)$ & \\
\hline Female & $34(24.46)$ & $17(21.79)$ & \\
\hline T category & & & 0.21 \\
\hline $\mathrm{T} 1$ & $61(43.88)$ & $33(42.31)$ & \\
\hline $\mathrm{T} 2$ & $43(30.94)$ & $16(20.51)$ & \\
\hline T3 & 20 (14.39) & $16(20.51)$ & \\
\hline T4 & 15 (10.79) & $13(16.67)$ & \\
\hline N category & & & 0.19 \\
\hline NO & $7(5.04)$ & $3(3.85)$ & \\
\hline N1 & 47 (33.81) & 19 (24.36) & \\
\hline N2 & $74(53.24)$ & $53(67.95)$ & \\
\hline N3 & $11(7.91)$ & $3(3.85)$ & \\
\hline Clinical stage & & & 0.13 \\
\hline$\|$ & 46 (33.09) & $18(23.08)$ & \\
\hline III & 69 (49.64) & $44(56.41)$ & \\
\hline IVA & $13(9.35)$ & 13 (16.67) & \\
\hline IVB & $11(7.91)$ & $3(3.85)$ & \\
\hline IC regimen & & & 0.11 \\
\hline $\mathrm{FP}$ & $16(11.51)$ & $13(16.67)$ & \\
\hline $\mathrm{TP}$ & $106(76.26)$ & $49(62.82)$ & \\
\hline other & $17(12.23)$ & $16(20.51)$ & \\
\hline IC cycles & & & 0.78 \\
\hline$\leq 2$ cycles & 81 (58.27) & $47(60.26)$ & \\
\hline$>2$ cycles & $58(41.73)$ & 31 (39.74) & \\
\hline
\end{tabular}

IC induction chemotherapy, ICRT induction chemotherapy plus radiotherapy, ICCCRT concurrent chemotherapy plus radiotherapy, TP docetaxel/paclitaxel plus cisplatin, $F P$ cisplatin plus fluorouracil

were $91.37 \%$ vs. $93.60 \%(p=0.56)$, and $61.87 \%$ vs. $66.67 \%$ $(p=0.46)$, respectively. The median follow-up of all patients was 62 months. There was no significant difference in median OS (61.87 vs. 60.33 months; $p=0.84$ ) and median PFS (60.87 vs. 60.33 months; $p=0.19$ ) between IC/ RT and IC/CCRT arms. Up to the date of final analysis, 27 people died in the IC/RT arm, and 14 died in the IC/ CCRT arm. The 3-year OS, PFS rates were $79.1 \%$, $64.7 \%$ for the IC/RT arm, and $86.1 \%, 80.5 \%$ for the IC/CCRT arm, respectively. The 5-year OS, PFS rates were $57.5 \%$, $41.8 \%$ for the IC/RT arm, and $47.8 \%, 38.4 \%$ for the IC/ CCRT arm, respectively. There was no significant difference in survival between the two groups as shown in Table 2 and Fig. 2. There was also no significant difference
Table 2 Comparison of the survival rates for ICRT VS ICCCRT

\begin{tabular}{lll}
\hline Variable & ICRT arm & ICCCRT arm \\
\hline OS (\%) & & \\
At 3-years & 79.1 & 86.1 \\
At 5-years & 57.5 & 47.8 \\
PFS (\%) & & \\
At 3-years & 64.7 & 80.5 \\
At 5-years & 41.8 & 38.4 \\
\hline
\end{tabular}

ICRT induction chemotherapy plus radiotherapy, ICCCRT concurrent chemotherapy plus radiotherapy

in subgroup survival analysis according to stage T3-4 category and N2-3 category ( $p>0.05$, Fig. 3$)$.

\section{Prognostic factors}

Table 3 shows the results of univariate and multivariate analysis with the Cox proportional hazards model. It shows that age and $\mathrm{N}$ category were significant prognostic factors for both OS and PFS, and T category was a significant prognostic factor for OS. Treatment modality (IC/RT vs. IC/CCRT) was not correlated with survival for either OS or PFS.

\section{Toxicities}

The most common toxicities related to treatment were listed in Table 4. There were no treatment-related deaths and grade 3-4 of kidney disfunction toxicities observed in our study. There were no significant differences of acute hematological toxicities and grade 3-4 non hematological adverse events between the two groups $(p>0.05)$ during the course of IC.

The IC/CCRT arm showed significantly higher rates of grade 3-4 leukopenia/neutropenia (3.60\% vs. $20.51 \%, p<0.001$ ), gastrointestinal disorder (nausea/ vomiting/diarrhea, $2.16 \%$ vs. $41.03 \%, p<0.001$ ), mucositis $(29.50 \%$ vs. $47.44 \%, p=0.01)$, and xerostomia (34.53\% vs. $48.72 \%, p=0.04$ ) compared with the IC/RT arm. No significant differences in thrombocytopenia, anemia, skin reaction ear problems (deafness/otitis), cranial neuropathy, and neck tissue damage were found between the two arms $(p>0.05)$.

\section{Discussion}

In this study, the survival outcomes and toxicities between IC followed by VMAT alone and IC plus CCRT in the treatment of stage II-IVB NPC patients were compared. There was no significant difference in OS and PFS observed for the addition of CC to VMAT after IC compared with IC plus VMAT alone. However, the risk of adverse effects, such as leukopenia/neutropenia, gastrointestinal events, mucositis and xerostomia were increased with the addition of CC. 

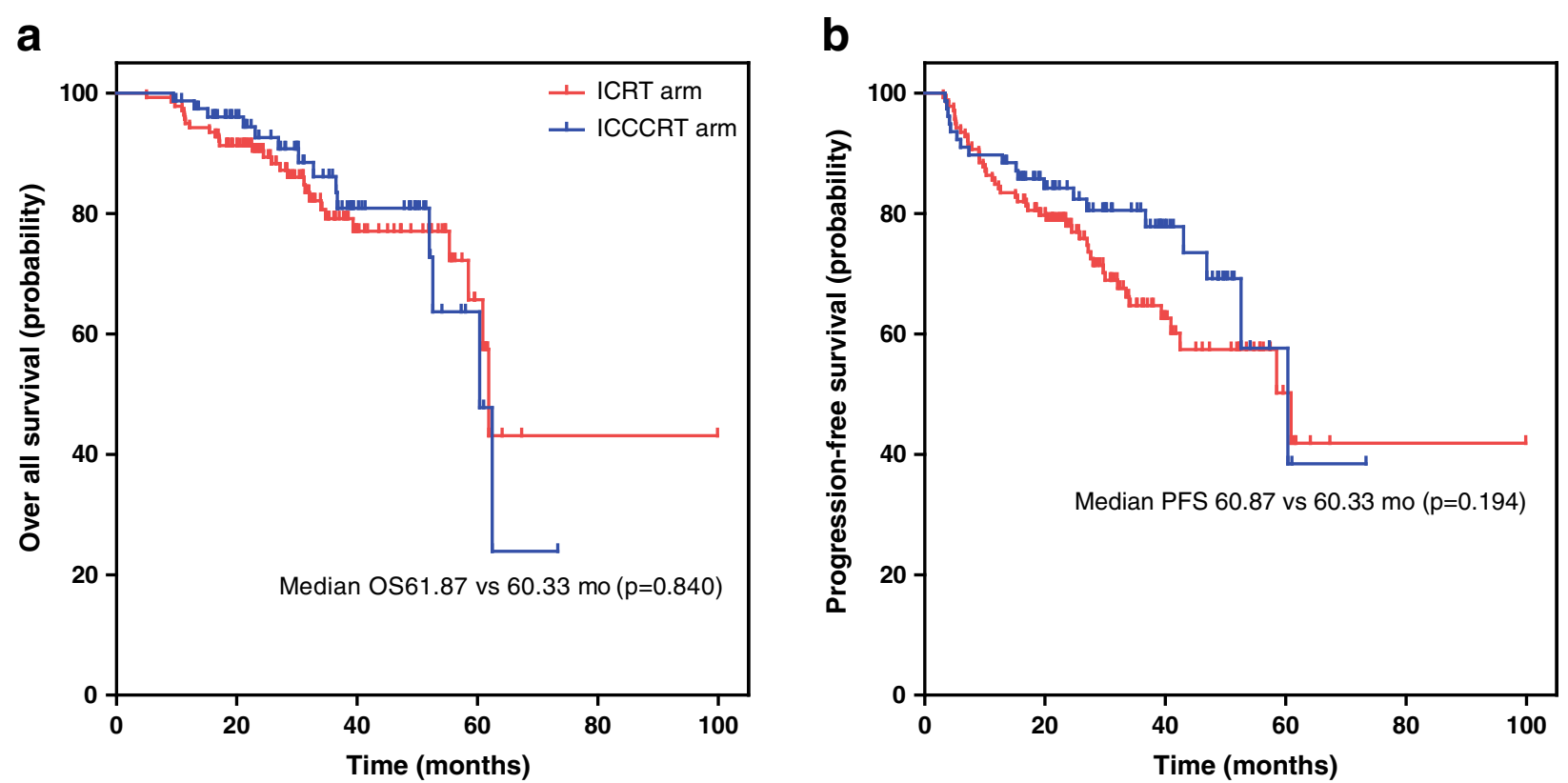

Fig. 2 Kaplan-Meier survival curves for stage II-IVB NPC patients in the ICRT and ICCCRT arms. a overall survival b progression-free survival

The efficacy of chemotherapy plus conventional radiotherapy has been confirmed in many clinical researches $[8,20-22]$, but the best sequence of chemotherapy with RT has not been well concluded and the value of CC added to VMAT after IC remains unknown. IC followed by $\mathrm{RT}$ alone had been reported to achieve benefit in response rate (RR) [15], DFS [14], reduce regional recurrence and distant metastasis $[3,4,23]$. In this study, IC plus VMAT alone also provided satisfactory outcomes with a DCR of $91.37 \%$ and an ORR of $61.87 \%$ at 3 months after RT.

The benefit of IC/CCRT in the treatment of NPC is still controversial. Sun et al. [4] demonstrated that IC/CCRT significantly improved OS, FFS rates of NPC patients. Tan et al. [24] also reported a 3-year OS rate of $94.3 \%$ in NPC with IC/CCRT. However, several trials failed to achieve superior survival outcomes by adding CC with RT after IC compared with IC/RT alone. Lin et al. [23] stated that additional CC to IC/RT offered no significant advantage for further improvement of local and regional control. Huang et al. [9] reached a similar conclusion in their study. In the trial conducted by Su et al. [25], NPC patients had similar OS, MFS, and DFS when treated with RT-based modalities, including IC plus RT, IC plus CCRT. In this study, VMAT was applied as the RT method in evaluation the efficacy and toxicities of IC/RT and IC/CCRT in the treatment of NPC. We also failed to observe a better outcome for IC/CCRT with VMAT in terms of either OS $(p=0.84)$ or PFS $(p=0.19)$ compared with IC plus VMAT alone. Multivariate analysis also indicated that CC was not an independent prognostic factor for either OS or PFS.
It is believed that local recurrence and distant metastasis are the major causes of failure in the treatment of NPC patients [26-29]. The ability of CC to control distant metastasis was relatively limited according to many studies [30-32]. Compared with CC, IC is capable of delivering chemotherapy drugs through the vasculature and eradicating micrometastases more effectively by administering the drugs before radiotherapy. It is expected to regress tumor extension, increase tumor radio-sensitivity, protect normal tissue at risk, prevent tumor progression due to the long waiting time before RT, and finally improve the local and distant control [33, 34]. On the other hand, IC is more likely to be tolerated by patients in the initial stage of treatment [35], thus increases their compliance [36]. More importantly, the shrunk primary lesions after IC can provide a wider boundary for RT, which is particularly important for NPC patients with tumor invasion or in close proximity to many critical normal tissues [37-39]. In this study, promising results on 3-year OS, PFS rates $(79.1 \%$, 64.7\%) and median OS and PFS (61.87 and 60.87 months) were achieved with IC/RT for NPC patients.

IMRT is able to escalate the dose to the target while sparing the adjacent critical structures [40, 41], and has shown remarkable benefits in local control and relapse-free survival of NPC patients [31, 42, 43]. IMRT/VMAT has been widely applied clinically in the treatment of NPC. Lin et al. [23] reported that there were no significant differences in distant disease-free survival (DDFS), DFS, OS (84.5\% vs. $82.6 \%$ vs. $89.1 \%$ and $85.8 \%$ vs. $80.3 \%, 89.2 \%)$ between IMRT alone and IMRT plus CC group $(p>0.05)$. 

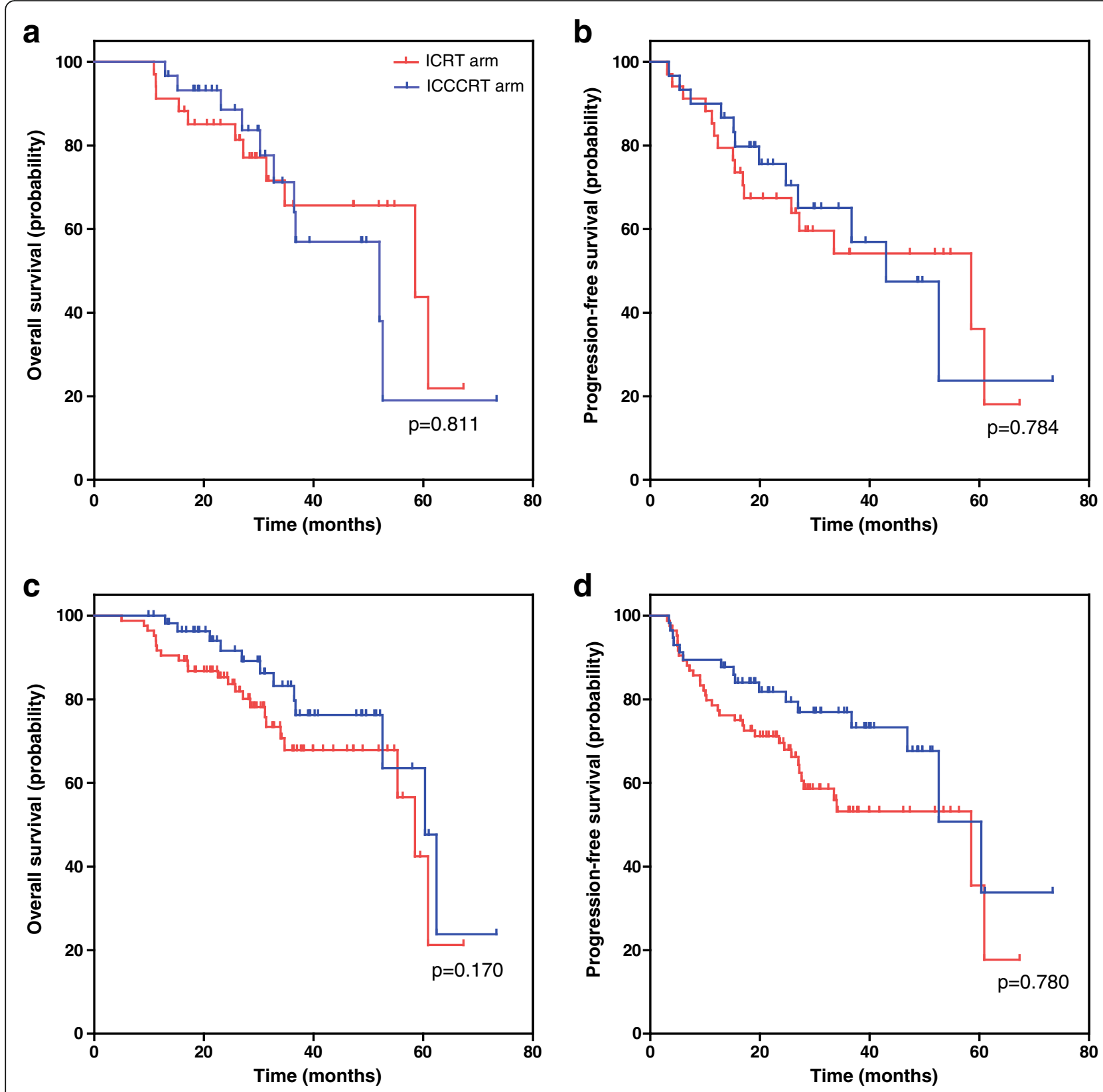

Fig. 3 Kaplan-Meier survival curves for subgroup patients with NPC in the ICRT and ICCCRT arms. a overall survival for NPC with T3-4 category b progression-free survival for NPC with T3-4 category. c overall survival for NPC with N2-3 category d progression-free survival for NPC with N2-3 category

Drug-related adverse effects of CC lead to the interruption of treatment in many NPC patients [22, 44, 45]. In the INT-0099 trial [8], the proportion of patients who completed the scheduled CC was only $63 \%$ due to excess toxicities. Lin et al. [23] and Sun et al. [28] reported that the total occurrence rates of grade 3-4 acute toxicities in patients receiving $\mathrm{CC}$ were higher than those receiving $\mathrm{RT}$ alone. Our study also demonstrated that additional CC increased the occurrence rates of grade 3-4 toxicities, especially leukopenia/neutropenia $(p<0.001)$, gastrointestinal events (nausea/vomiting/diarrhea) $(p<0.001)$, mucositis $(p=0.01)$ and xerostomia $(p=0.04)$. These serious toxicities could obviously reduce the compliance of patients during CCRT.

One limitation of current study is that this is a retrospective methodology from a single-institution experience. The impact of various treatments related outcomes could not be fully evaluated. The number of patients enrolled may not be sufficient enough and the follow-up duration of the study may not be long enough. External validation 
Table 3 Univariate and multivariate analysis of the associations between factors affecting OS and PFS in patients

\begin{tabular}{|c|c|c|c|}
\hline \multirow[t]{2}{*}{ Outcome } & \multirow{2}{*}{$\begin{array}{l}\text { Univariate } \\
P \text {-value }\end{array}$} & \multicolumn{2}{|l|}{ Multivariate } \\
\hline & & Hazard ratio $(95 \% \mathrm{Cl})$ & $P$-value \\
\hline \multicolumn{4}{|l|}{ Overall survival } \\
\hline Sex female vs. male & 0.24 & $0.57(0.22-1.47)$ & 0.24 \\
\hline Age $\leq 54$ years vs. $>54$ years & $0.003^{\mathrm{a}}$ & $0.43(0.22-0.82)$ & $0.01^{a}$ \\
\hline T category T1-2 vs.T3-4 & $0.001^{\mathrm{a}}$ & $0.52(0.27-0.99)$ & $0.046^{\mathrm{a}}$ \\
\hline N category N0-1vs. N2-3 & $0.001^{\mathrm{a}}$ & $0.34(0.13-0.85)$ & $0.02^{\mathrm{a}}$ \\
\hline Treatment arm ICRT vs. IC/CCRT & 0.84 & $1.35(0.70-2.61)$ & 0.37 \\
\hline \multicolumn{4}{|l|}{ Progression-free survival } \\
\hline Sex female vs. male & 0.49 & $0.74(0.39-1.39)$ & 0.34 \\
\hline Age $\leq 54$ years vs. $>54$ years & $<0.001^{\mathrm{a}}$ & $0.36(0.21-0.60)$ & $<0.001^{\mathrm{a}}$ \\
\hline T category T1-2 vs.T3-4 & $0.01^{\mathrm{a}}$ & $0.67(0.40-1.14)$ & 0.14 \\
\hline N category N0-1 vs. N2-3 & $0.003^{\mathrm{a}}$ & $0.49(0.26-0.93)$ & $0.03^{\mathrm{a}}$ \\
\hline Treatment arm ICRT vs. IC/CCRT & 0.19 & $1.62(0.94-2.79)$ & 0.08 \\
\hline
\end{tabular}

ICRT induction chemotherapy plus radiotherapy, ICCCRT concurrent chemotherapy plus radiotherapy, $\mathrm{Cl}$ confidence interval ${ }^{\mathrm{a}}$ statistical significant

Table 4 Profile of treatment-related toxicities

\begin{tabular}{|c|c|c|c|}
\hline & $\begin{array}{l}\text { ICRT arm } \\
(n=139)\end{array}$ & $\begin{array}{l}\text { IC/CCRT arm } \\
(n=78)\end{array}$ & $P$-value \\
\hline \multicolumn{4}{|c|}{ Grade 3-4 adverse events during IC, n (\%) } \\
\hline \multicolumn{4}{|l|}{ Hematological } \\
\hline Leukopenia/neutropenia & $26(18.71)$ & $20(25.64)$ & 0.23 \\
\hline Thrombocytopenia & $1(0.72)$ & $0(0)$ & 1.00 \\
\hline Anemia & $2(1.44)$ & $0(0)$ & 0.54 \\
\hline \multicolumn{4}{|l|}{ Non-Hematological } \\
\hline Nausea/vomiting/diarrhea & $23(16.55)$ & $12(15.38)$ & 0.82 \\
\hline Liver disfunction & $0(0)$ & $2(2.56)$ & 0.13 \\
\hline Kidney disfunction & $0(0)$ & $0(0)$ & NA \\
\hline \multicolumn{4}{|c|}{ Grade 3-4 adverse events during RT, n (\%) } \\
\hline \multicolumn{4}{|l|}{ Hematological } \\
\hline Leukopenia/neutropenia & $5(3.60)$ & $16(20.51)$ & $<0.001^{\mathrm{a}}$ \\
\hline Thrombocytopenia & $2(1.44)$ & $4(5.13)$ & 0.19 \\
\hline Anemia & $2(1.44)$ & $2(2.56)$ & 0.30 \\
\hline \multicolumn{4}{|l|}{ Non-Hematological } \\
\hline Nausea/vomiting/diarrhea & $3(2.16)$ & $32(41.03)$ & $<0.001^{\mathrm{a}}$ \\
\hline Skin reaction & $58(41.73)$ & $39(50.00)$ & 0.24 \\
\hline Mucositis & $41(29.50)$ & $37(47.44)$ & $0.01^{\mathrm{a}}$ \\
\hline \multicolumn{4}{|l|}{ Grade 3-4 late toxicities } \\
\hline Xerostomia & $48(34.53)$ & $38(48.72)$ & $0.04^{\mathrm{a}}$ \\
\hline Ear (deafness/otitis) & $39(28.06)$ & $27(34.62)$ & 0.31 \\
\hline Cranial neuropathy & $9(6.47)$ & $4(5.13)$ & 0.69 \\
\hline Neck tissue damage & $28(20.14)$ & $24(30.77)$ & 0.08 \\
\hline
\end{tabular}

IC induction chemotherapy, $R T$ radiotherapy, ICRT induction chemotherapy plus radiotherapy, ICCCRT concurrent chemotherapy plus radiotherapy, NA none available

${ }^{a}$ statistical significant using other large database for further evaluating the role of CC for NPC.

\section{Conclusion}

In summary, there was no significant benefits on survival observed with IC/CCRT compared with IC/RT alone in the treatment of stage II-IVB NPC patients. On the contrary, more severe side effects were associated with $\mathrm{IC/}$ CCRT. CC should be used with caution in the treatment of NPC combined with IC and VMAT.

\section{Abbreviations}

2D-CRT: Two-dimensional conventional radiotherapy; CCRT: Concurrent chemotherapy; CT: Computed tomography; CTCAE: Common Terminology Criteria for Adverse Events; CTV: The first clinical tumor volume; CTV2: The second CTV; DCR: Disease control rate; DFS: Disease-free survival; FP: Cisplatin plus fluorouracil; GTV: Gross tumor volume; IC: Induction chemotherapy; IMRT: Intensity-modulated radiotherapy; MRI: Magnetic resonance imaging; NPC: Nasopharyngeal carcinoma; OS: Overall survival; PFS: Progression-free survival; PTV: Planning target volume; RECIST: Response evaluation criteria in solid tumors; RR: Response rates; RT: Radiotherapy; SIB: Simultaneous integrated boost; TP: Docetaxel/paclitaxel plus cisplatin; TPS: Treatment planning system

\section{Funding}

The study was partially funded by National Natural Science Foundation of China (grant number 11675122), Natural Science Foundation of Zhejiang Province (grant number $\mathrm{LY} 16 \mathrm{H} 160046$ and $\mathrm{Y} 17 \mathrm{H} 160051)$.

\section{Availability of data and materials}

The datasets used and/or analysed during the current study are available from the corresponding author on reasonable request.

\section{Authors' contributions}

$\mathrm{LL}$ and FZ carried out data analyses and drafted the manuscript. $C M, Z \mathrm{~L}$, $S H, G D, L B$ did the follow up; CX, LL, GM, YX performed the statistical analysis. JX, XC designed, coordinated, and supervised the study and critically reviewed and discussed the manuscript. All authors have read and approved the final version of the manuscript. 


\section{Ethics approval and consent to participate}

All procedures performed in studies involving human participants were in accordance with the ethical standards of the institutional and/or national research committee and with the 1964 Helsinki declaration and its later amendments or comparable ethical standards. This study was approved by the Regional Ethics Committee of the First Affiliated Hospital of Wenzhou Medical University.

\section{Consent for publication}

Not applicable.

\section{Competing interests}

The authors declare that they have no competing interests.

\section{Publisher's Note}

Springer Nature remains neutral with regard to jurisdictional claims in published maps and institutional affiliations.

\section{Author details}

'Department of Radiation and Medical Oncology, The First Affiliated Hospital of Wenzhou Medical University, No.2 Fuxue Lane, Wenzhou 325000, China. ${ }^{2}$ Department of Oncology Medicine, Yueqing 3rd People's Hospital, Wenzhou 325600, China.

\section{Received: 16 June 2018 Accepted: 2 August 2018}

\section{Published online: 13 August 2018}

\section{References}

1. Liang SB, Wang Y, Hu XF, He SS, Yang XL, Liu LZ, et al. Survival and toxicities of IMRT based on the RTOG protocols in patients with nasopharyngeal carcinoma from the endemic regions of China. J Cancer. 2017;8:3718-24.

2. National Comprehensive Cancer Network. NCCN Guidelines ${ }^{\oplus}$. 2018. https:// www.nccn.org/professionals/physician_gls/default.aspx\#head-and-neck. Accessed 15 Feb 2018

3. Blanchard P, Lee A, Marguet S, Leclercq J, Ng WT, Ma J, et al. Chemotherapy and radiotherapy in nasopharyngeal carcinoma: an update of the MAC-NPC meta-analysis. Lancet Oncol. 2018;16:645-55.

4. Sun Y, Li WF, Chen NY, Zhang N, Hu GQ, Xie FY, et al. Induction chemotherapy plus concurrent chemoradiotherapy versus concurrent chemoradiotherapy alone in locoregionally advanced nasopharyngeal carcinoma: a phase 3, multicentre, randomised controlled trial. Lancet Oncol. 2016;17:1509-20.

5. Peng H, Chen L, Zhang J, Li WF, Mao YP, Zhang Y, et al. Induction chemotherapy improved long-term outcomes of patients with locoregionally advanced nasopharyngeal carcinoma: a propensity matched analysis of 5-year survival outcomes in the era of intensity-modulated radiotherapy. J Cancer. 2017:8(3):371-7.

6. Hui EP, Ma BB, Leung SF, King AD, Mo F, Kam MK, et al. Randomized phase II trial of concurrent cisplatin-radiotherapy with or without neoadjuvant docetaxel and cisplatin in advanced nasopharyngeal carcinoma. J Clin Oncol. 2009;27:242-9.

7. Qiu WZ, Huang PY, Shi JL, Xia HQ, Zhao C, Cao KJ. Neoadjuvant chemotherapy plus intensity-modulated radiotherapy versus concurrent chemoradiotherapy plus adjuvant chemotherapy for the treatment of locoregionally advanced nasopharyngeal carcinoma: a retrospective controlled study. Chin J Cancer. 2016;35:2

8. Al-Sarraf M, LeBlanc M, Giri PG, Fu KK, Cooper J, Vuong T, et al. Chemoradiotherapy versus radiotherapy in patients with advanced nasopharyngeal cancer: phase III randomized intergroup study 0099. J Clin Oncol. 1998;16(4):1310-7.

9. Huang PY, Cao KJ, Guo X, Mo HY, Guo L, Xiang YQ, et al. A randomized trial of induction chemotherapy plus concurrent chemoradiotherapy versus induction chemotherapy plus radiotherapy for locoregionally advanced nasopharyngeal carcinoma. Oral Oncol. 2012;48:1038-44.

10. Dilruba S, Kalayda GV. Platinum-based drugs: past, present and future Cancer Chemother Pharmacol. 2016;77:1103-24.

11. Toumi N, Ben Kridis W, Mnejja W, Bouzguenda R, Khanfir A, Ghorbel A, et al. TPF induction chemotherapy followed by concurrent chemoradiotherapy for locally advanced nasopharyngeal carcinoma: long term results of a Tunisian series. Cancer Radiother. 2018;22(3):216-21.
12. Li WF, Li YQ, Chen L, Zhang Y, Guo R, Zhang F, et al. Propensitymatched analysis of three different chemotherapy sequences in patients with locoregionally advanced nasopharyngeal carcinoma treated using intensity-modulated radiotherapy. BMC Cancer. 2015;15:810.

13. Zhang B, Hu Y, Xiong RH, Pan YF, Xu QL, Kong XY, et al. Matched analysis of induction chemotherapy plus chemoradiotherapy versus induction chemotherapy plus radiotherapy alone in locoregionally advanced nasopharyngeal carcinoma: a multicenter study. Oncotarget. 2017; https:// doi.org/10.18632/oncotarget.13285.

14. Ma J, Mai HQ, Hong MH, Min HQ, Mao ZD, Cui NJ, et al. Results of a prospective randomized trial comparing neoadjuvant chemotherapy plus radiotherapy with radiotherapy alone in patients with locoregionally advanced nasopharyngeal carcinoma. J Clin Oncol. 2001;19:1350-7.

15. International Nasopharynx Cancer Study Group. Preliminary results of a randomized trial comparing neoadjuvant chemotherapy (cisplatin, epirubicin, bleomycin) plus radiotherapy vs. radiotherapy alone in stage IV ( $\mathrm{N}$ or $=\mathrm{N} 2, \mathrm{M} 0)$ undifferentiated nasopharyngeal carcinoma. Int J Radiat Oncol Biol Phys. 1996;35:463-9.

16. Jin X, Yi J, Zhou Y, Yan H, Han C, Xie C. Comparison of whole-field simultaneous integrated boost VMAT and IMRT in the treatment of nasopharyngeal cancer. Med Dosim. 2013;38:418-23.

17. Zhao W, Lei H, Zhu X, Li L, Song Q, Liang X. Investigation of long-term survival outcomes and failure patterns of patients with nasopharyngeal carcinoma receiving intensity-modulated radiotherapy. Oncotarget. 2016; https://doi.org/10.18632/oncotarget.13564.

18. Tang C, Wu F, Wang R, Lu H, Li G, Liu M, et al. Comparison between nedaplatin and cisplatin plus docetaxel combined with intensity-modulated radiotherapy for locoregionally advanced nasopharyngeal carcinoma: a multicenter randomized phase II clinical trial. Am J Cancer Res. 2006;6:2064-75.

19. Wu SX, Xie CY, Jin XC, Zhang P. Simultaneous modulated accelerated radiation therapy in the treatment of nasopharyngeal cancer: a local center's experience. Int J Radiat Oncol Biol Phys. 2006;87:s40-6.

20. Langendijk JA, Leemans CR, Buter J, Berkhof J, Slotman BJ. The additional value of chemotherapy to radiotherapy in locally advanced nasopharyngeal carcinoma: a meta-analysis of the published literature. J Clin Oncol. 2006;22: 4604-12.

21. OuYang PY, Xie C, Mao YP, Zhang Y, Liang XX, Su Z, et al. Significant efficacies of neoadjuvant and adjuvant chemotherapy for nasopharyngeal carcinoma by meta-analysis of published literature-based randomized, controlled trials. Ann Oncol. 2013;24:2136-46.

22. Wee J, Tan EH, Tai BC, Wong HB, Leong SS, Tan T, et al. Randomized trial of radiotherapy versus concurrent chemoradiotherapy followed by adjuvant chemotherapy in patients with American Joint Committee on Cancer/ International Union against cancer stage III and IV nasopharyngeal cancer of the endemic variety. J Clin Oncol. 2005;23:6730-8.

23. Lin S, Lu JJ, Han L, Chen Q, Pan J. Sequential chemotherapy and intensity-modulated radiation therapy in the management of locoregionally advanced nasopharyngeal carcinoma: experience of 370 consecutive cases. BMC Cancer. 2010;10:39.

24. Tan T, Lim WT, Fong KW, Cheah SL, Soong YL, Ang MK, et al. Concurrent chemo-radiation with or without induction gemcitabine, carboplatin, and paclitaxel: a randomized, phase 2/3 trial in locally advanced nasopharyngeal carcinoma. Int J Radiat Oncol Biol Phys. 2015;91:952-60.

25. Su SF, Han F, Zhao C, Huang Y, Chen CY, Xiao WW, et al. Treatment outcomes for different subgroups of nasopharyngeal carcinoma patients treated with intensity-modulated radiation therapy. Chin J Cancer. 2011;30:565-73.

26. Lee N, Harris J, Garden AS, Straube W, Glisson B, Xia P, et al. Intensitymodulated radiation therapy with or without chemotherapy for nasopharyngeal carcinoma: radiation therapy oncology group phase II trial 0225. J Clin Oncol. 2009;27:3684-90.

27. Peng G, Wang $T$, Yang KY, Zhang S, Zhang T, Li Q, et al. A prospective, randomized study comparing outcomes and toxicities of intensity-modulated radiotherapy vs. conventional two-dimensional radiotherapy for the treatment of nasopharyngeal carcinoma. Radiother Oncol. 2012;104:286-93.

28. Sun X, Su S, Chen C, Han F, Zhao C, Xiao W, et al. Long-term outcomes of intensity-modulated radiotherapy for 868 patients with nasopharyngeal carcinoma: an analysis of survival and treatment toxicities. Radiother Oncol. 2014;110:398-403.

29. Chen C, Chen T, Huang C, Wang J, Fei Z. Experience of weekly cisplatin concurrent with intensity-modulated radiotherapy for locally advanced nasopharyngeal carcinoma patients with resistance to neoadjuvant 
chemotherapy. Medicine. 2017; https://doi.org/10.1097/MD 0000000000008434

30. Chua DT, Ma J, Sham JS, Mai HQ, Choy DT, Hong MH, et al. Long-term survival after cisplatin-based induction chemotherapy and radiotherapy for nasopharyngeal carcinoma: a pooled data analysis of two phase III trials. J Clin Oncol. 2005;23:1118-24.

31. Lee AW, Tung SY, Ngan RK, Chappell R, Chua DT, Lu TX, et al. Factors contributing to the efficacy of concurrent-adjuvant chemotherapy for locoregionally advanced nasopharyngeal carcinoma: combined analyses of NPC-9901 and NPC-9902 trials. Eur J Cancer. 2011;47:656-66.

32. Lin J-C, Liang W-M, Jan J-S, Jiang R-S, Lin AC. Another way to estimate outcome of advanced nasopharyngeal carcinoma-is concurrent chemoradiotherapy adequate? Int J Radiat Oncol. 2004; https://doi.org/10. 1016/j.jijobp.2004.03.002.

33. Wu LR, Jiang XS, Song $X$, Yu HL, Fan YX, Wang FJ, et al. Comparing the efficacy of induction-concurrent with concurrent-adjuvant chemotherapy in locoregionally advanced nasopharyngeal carcinoma: a propensity score matching analysis. Oncotarget. 2017; https://doi.org/10.18632/ oncotarget.20389.

34. Golden DW, Rudra S, Witt ME, Nwizu T, Cohen EE, Blair E, et al. Outcomes of induction chemotherapy followed by concurrent chemoradiation for nasopharyngeal carcinoma. Oral Oncol. 2013:49:277-82.

35. Frikha M, Auperin A, Tao Y, Elloumi F, Toumi N, Blanchard P, et al. A randomized trial of induction docetaxel-cisplatin-5FU followed by concomitant cisplatin-RT versus concomitant cisplatin-RT in nasopharyngeal carcinoma (GORTEC 2006-02). Ann Oncol. 2018:29(3):731-6.

36. Fountzilas G, Ciuleanu E, Bobos M, Kalogera-Fountzila A, Eleftheraki AG, Karayannopoulou G, et al. Induction chemotherapy followed by concomitant radiotherapy and weekly cisplatin versus the same concomitant chemoradiotherapy in patients with nasopharyngeal carcinoma: a randomized phase II study conducted by the Hellenic Cooperative Oncology Group (HeCOG) with biomarker evaluation. Ann Oncol. 2012:23:427-35.

37. Al-Amro A, Al-Rajhi N, Khafaga Y, Memon M, Al-Hebshi A, El-Enbabi A, et al. Neoadjuvant chemotherapy followed by concurrent chemo-radiation therapy in locally advanced nasopharyngeal carcinoma. Int J Radiat Oncol Biol Phys. 2005;62:508-13.

38. Johnson FM, Garden AS, Palmer JL, Shin DM, Morrison W, Papadimitrakopoulou V, et al. A phase I/II study of neoadjuvant chemotherapy followed by radiation with boost chemotherapy for advanced T-stage nasopharyngeal carcinoma. Int J Radiat Oncol Biol Phys. 2005;63:717-24

39. Oh JL, Vokes EE, Kies MS, Mittal BB, Witt ME, Weichselbaum RR, Haraf DJ, et al. Induction chemotherapy followed by concomitant chemoradiotherapy in the treatment of locoregionally advanced nasopharyngeal cancer. Ann Oncol. 2003;14:564-9.

40. Kwong DL, Pow EH, Sham JS, McMillan AS, Leung LH, Leung WK, et al. Intensity-modulated radiotherapy for early-stage nasopharyngeal carcinoma: a prospective study on disease control and preservation of salivary function. Cancer. 2004;101(7):1584-93.

41. Laskar S, Bahl G, Muckaden M, Pai SK, Gupta T, Banavali S, et al. Nasopharyngeal carcinoma in children: comparison of conventional and intensity-modulated radiotherapy. Int J Radiat Oncol Biol Phys. 2008;72:728-36.

42. Lai SZ, Li WF, Chen L, Luo W, Chen YY, Liu LZ, et al. How does intensitymodulated radiotherapy versus conventional two-dimensional radiotherapy influence the treatment results in nasopharyngeal carcinoma patients? Int J Radiat Oncol Biol Phys. 2011;80:661-8.

43. Xue F, Hu C, He X. Induction chemotherapy followed by intensity-modulated radiotherapy with reduced gross tumor volume delineation for stage T3-4 nasopharyngeal carcinoma. Oncotargets Ther. 2017;10:3329-36.

44. Cheng SH, Jian JJ, Tsai SY, Yen KL, Chu NM, et al. Long-term survival of nasopharyngeal carcinoma following concomitant radiotherapy and chemotherapy. Int J Radiat Oncol Biol Phys. 2000;48:1323-30.

45. Ke LR, Xia WX, Qiu WZ, Huang XJ, Yang J, Yu YH, et al. Safety and efficacy of lobaplatin combined with 5-fluorouracil as first-line induction chemotherapy followed by lobaplatin-radiotherapy in locally advanced nasopharyngeal carcinoma: preliminary results of a prospective phase II trial. BMC Cancer. 2017:17:134.

\section{Ready to submit your research? Choose BMC and benefit from:}

- fast, convenient online submission

- thorough peer review by experienced researchers in your field

- rapid publication on acceptance

- support for research data, including large and complex data types

- gold Open Access which fosters wider collaboration and increased citations

- maximum visibility for your research: over $100 \mathrm{M}$ website views per year

At BMC, research is always in progress.

Learn more biomedcentral.com/submissions 